\title{
Radiation and Thermal Effects in Experimental High Dense Metal Fuel Elements for Advanced LMFR
}

\author{
Golovchenko Yulian \\ Joint Stock Company, State Scientific Center, \\ Research Institute of Atomic Reactors, Dimitrovgrad, 433510, Ulyanovsk region, Russia
}

Received 2013-01-09, Revised 2013-03-29; Accepted 2013-07-02

\begin{abstract}
Known disadvantages of high-dense $\alpha-\mathrm{U}$ metal fuel (intense radiation growth and radiation swelling, poor compatibility with steel claddings) can be reduced to the minimum by "constructive" approaches based on mechanical restraint of radiation growth and swelling and also on application of protective layers on fuel columns and claddings. Effectiveness of these methods has been confirmed during irradiation of full-sized fuel pins with high-dense metal fuel $\left(\gamma_{\mathrm{eff}} \geq 12.5 \mathrm{~g}\right.$ h.a. $\left./ \mathrm{cm}^{3}\right)$ in the BOR-60 and BN-350 reactors.
\end{abstract}

Keywords: Radiation, Constructive, Effectiveness, During Irradiation, Protective Layers

\section{INTRODUCTION}

Potential advantages of nuclear U-metal fuel over nonmetal fuels (oxide, carbide, nitride) are well-known (Emelyanov and Evstyukhin, 1969) in such important initial parameters as:

- Density by heavy atoms (it is maximal for alloy-free uranium)

- Thermal conductivity (at a room temperature it is maximal for alloy-free uranium and increases as temperature rises)

- During production technological effectiveness is high enough due to low strength and high plasticity of metal uranium at rather low temperatures

- Technological effectiveness is during postirradiation reprocessing (reprocessing can be possible by any used methods: aqueous, gas-fluoride or in the molten salts)

Actual differences of metal fuels (in particular, highdense fuels with minimum content of alloying additives) from non-metal fuels are also well-known in the following initial characteristics of practical importance:

- Intense radiation growth: $\left(\mathrm{G}=\frac{\Delta / 1 / 1_{0}, \%}{\mathrm{~B}, \%}=\mathrm{n}(10 \ldots . .100)\right)$
- Intense radiation swelling:

$$
\left(\mathrm{S}=\frac{\Delta \mathrm{v} / \mathrm{v}_{0}, \%}{\mathrm{~B}, \%}=\mathrm{n}(10 \ldots .100)\right)
$$

- Low melting temperature $\left(\mathrm{T}_{\text {melt }} \leq 1130^{\circ} \mathrm{C}\right)$

- Presence of low-temperature phase transformation with significant volume changes $\left(\mathrm{T}_{\alpha-\beta-\gamma} \leq 667\right.$ and $\left.772{ }^{\circ} \mathrm{C} ; \Delta_{\mathrm{V}} / \mathrm{V}_{0}=4,6 \ldots .7,8 \%\right)$

- Intense FCCI with steel claddings and low temperatures of eutectics formation with $\mathrm{Fe}$-parent component of cladding steels $\left(\mathrm{T}_{\text {eut }}=725^{\circ} \mathrm{C}\right.$ for U-Fe, $\mathrm{T}_{\text {eut }}=410^{\circ} \mathrm{C}$ for $\mathrm{Pu}-\mathrm{Fe}$ )

These initial data of high-dense metal fuels are usually considered unfavorable and prevent their application in the $\mathrm{BN}$ reactors under conditions of successful operation of oxide, carbide and nitride fuel pins.

This study deals with influence of some of these unfavorable initial properties characterizing high-dense metal fuels on radiation-thermal effects in experimental fuel pins as applied to their operation in the BN-type reactors to solve tasks inpro.

\subsection{Radiation Growth}

Known effects of uranium radiation growth (surface roughening, bowing and lengthening of fuel columns and 
fuel pins) can be limited by conventional "metallurgical" technique based on uranium alloying with small additives, thermal and thermal-mechanical treatment of fuel columns. This technique of fuel column production and corresponding methods of fuel column quality control find a wide application in the fabrication and commissioning of fuel pins containing alpha-uranium fine-grain fuel columns, which are texture-free. These fuel columns have nearly the maximal density and the minimum deformation because of radiation growth.

Application of similar "metallurgical" production technique and appropriate quality control methods of fuel columns primarily consisting of alpha-phase U-Pu alloys is sufficiently questionable. Obstacles are explained by necessity of realizing the technique and methods in the hot cells, which are difficult from the technical viewpoint. No attempts of such realizations are known.

Simplified techniques of fuel column fabrication, acceptable for application under hot cell conditions must imply no thermal and thermal-mechanical treatment of fuel columns and corresponding quality control methods. It is also obvious, that the simplified methods can't limit macroeffects of radiation growth in $\alpha$-phase fuel columns, namely: quasiisotropic coarse-grained or textured fine-grained fuel columns.

Strains and deformations of the claddings caused by macroeffects must be proportional to stresses that are generated during radiation growth by macrocrystals being located on the surface of quasiisotropic fuel column or textured fuel column on the whole. The stresses (radiation growth stresses $\sigma_{\mathrm{g}}$ ) were first estimated by Buckley (1966) and taken exceeding $20 \mathrm{MPa}$, as in his experiment compressive (restraining) stress $\sigma_{\text {compr. }}=20 \mathrm{MPa}$ did not prevent radiation growth of $\alpha$-uranium monocrystal.

This strengthens the existing opinion, that it is impossible to restrict macroeffects of $U$ radiation growth by any other ways different from "metallurgical" methods, which provide crushing and milling of grains and removal of texture in $\alpha-U$ fuel column.

Simplified "metallurgical" method for restriction of $\mathrm{U}$ radiation growth macroeffects is known and realized in the hot cell. It was developed at ANL (Kittel et al., 1993) and is based on doping of uranium and U-Pu alloys with metal additives (Fs, Fz, $\mathrm{Zr}$ ) in the quantity (5...12 wt.\%), sufficient for stabilization of isotropic gamma-phase of $U$ alloy. Fuel columns made of these alloys by injection casting are not subjected to difficult processing. But during irradiation in the fuel pins with sodium filling the fuel column produced according to this technique can lengthen by $12 \%$ (Lahm et al., 1993) resulting from macroeffects of free, mechanically unlimited radiation growth among other factors. Thus, the developed and realized at ANL method of alloying metal fuel with $\mathrm{Zr} 10$ wt. \%, restricts but does not exclude completely undesirable elongations of the fuel column caused by radiation growth. At the same time such alloying reduces fuel material density from $19 \mathrm{~g}$ to $14.3 \mathrm{~g}$ h.a. $/ \mathrm{cm}^{3}\left(15.8 \mathrm{~g} / \mathrm{cm}^{3}\right)$.

Stated above facts, results and their consequences were taken into consideration for arranging and carrying out at RIAR investigations on effects of mechanically limited radiation growth of high-dense $\alpha$-uranium metal fuels. The investigated fuels were greatly different in such initial characteristics as grain size (from fine grain to monocrystal), texturing degree and mechanical properties (from minimal to maximal values) Small-scale specimens, mockup fuel pins, experimental fuel pins and full-size FA, incorporating experimental fuel pins, were investigated. Correspondingly, irradiation was performed in water loops of the SM-2 reactor, in the sodium loop of the MIR reactor, in the core and radial blanket of the BOR-60 and BN-350.

Flowsheets of the experiments were shown in Fig. 1:

- Tube cases for uniform restraint deformation of flat mono- and polycrystalline specimens for tensile tests

- Tube cases for measuring stresses of radiation growth of mono- and polycrystalline cylindrical specimens by Al-cone yielding

- The same, polycrystalline specimen was extruded together with Zr-cladding and linked with it

- Annular specimen of polycrystalline uranium linked with Zr-cladding has no additional restraints for growth in axial direction

During irradiation and postirradiation examinations the following was established:

- Radiation growth of uranium monocrystals, polycrystalline textured specimens and full-size fuel columns can be mechanically limited within previously set limits. It is explained by the fact, that irradiated polycrystalline uranium had a sufficient ability to plastic strain under compressive loads

- Mechanical stress, restraining uranium radiation growth depends not only on degree of initial texturing, but also on initial mechanical properties. The measured radiation growth stresses are minimal for non-strengthened uranium monocrystal $\left(\sigma_{\mathrm{g}} \sim 70\right.$ $\mathrm{MPa})$ and maximal for high-strength alpha-phase composition of $\mathrm{U}-\mathrm{BeO}\left(\sigma_{\mathrm{g}}>230 \mathrm{MPa}\right)$ 


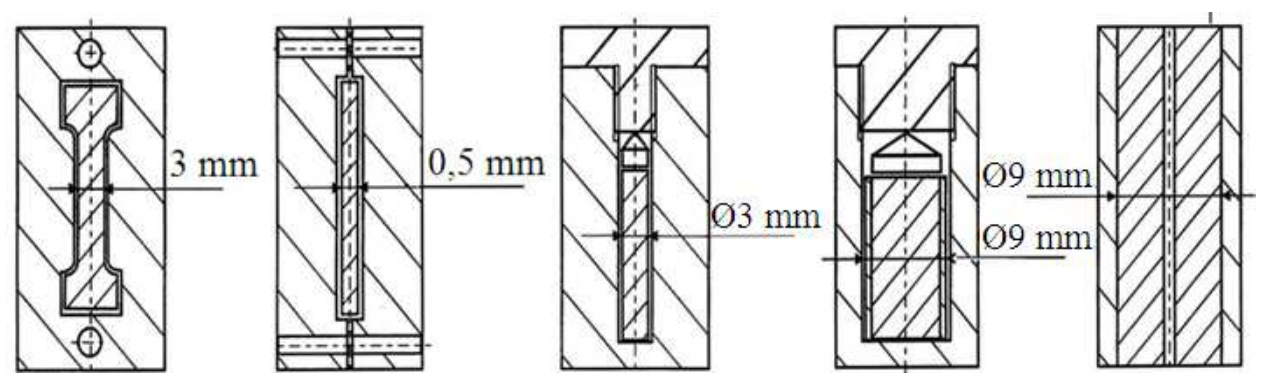

Fig. 1. Schematic diagram of devices for mechanical restraints of radiation growth of uranium specimens

The differences in $\sigma_{\mathrm{g}}$ explain differences in nature and values of the observed macroeffects of mechanically limited radiation growth of the fuel columns in experimental fuel pins. These effects include:

- Loss of longitudinal stability and multiwave flexure of fuel columns inside the cladding, which had initial texture of radiation growth longitudinally

- "Jamming" in claddings of the fuel columns, which had initial texture of radiation growth across-track direction, ovalization of claddings

- Roughening of cladding surfaces because of radiation growth of separate grains on the surface of quasi-isotropic fuel columns in crosswise direction

The results of the experiments indicate, that radiation growth macroeffects can be restricted by using not only "metallurgical" technique but also "constructive" approaches, which are not connected with necessity of removing initial texture and milling grains in fuel columns.

\subsection{Influence of Initial Composition and Structure on free and Mechanically Restrained Swelling of Uranium Alloys}

Known effects of uranium radiation swelling (in particular cavitation and gas swellings) can be also limited by conventional "metallurgical" technique.

Despite predicted difficulty in case of applying this technique during fabrication of high-level Pu-bearing metal fuels under hot cell conditions, in spite of obvious decrease in heavy-atoms $(\mathrm{U}, \mathrm{Pu})$ concentration in doped alloys, we studied influence of various alloying additives and thermal treatment on free radiation swelling of uranium alloys under wide variations of such parameters as temperature, burnup rate, burnup.

Small-scale specimens were irradiated in the SM-2 reactor using capsules filled with sodium. Specimens of more than 200 alloys represented both well-known and poorly studied "metallurgical" ways of controlling composition, structure and initial characteristics of uranium alloys. They were specimens of alloy-free uranium, low-, medium-and high-doped alloys, metallicceramic compositions and composite materials. Content of soluble additives (Mo, $\mathrm{Zr}, \mathrm{Nb}, \mathrm{Ti}$ ) in alloys was as much as $40 \mathrm{wt}$. \%. Content of insoluble additives $\left(\mathrm{BeO}, \mathrm{UO}_{2}\right.$, $\mathrm{ThO}_{2}, \mathrm{ZrC}$ ) achieved $15 \mathrm{wt}$. \%. Swelling rate was taken as a criterion of swelling resistance:

$$
\mathrm{S}=\frac{\Delta \mathrm{v} / \mathrm{v}_{0}, \%}{\mathrm{~B}, \%}
$$

Where:

$$
\begin{array}{ll}
\Delta_{\mathrm{V}} / \mathrm{V}_{0} & =\text { Swelling, } \% \\
\mathrm{~B} & =\text { Burnup, } \% \text { h.a }
\end{array}
$$

In-pile tests and post irradiation examinations showed, that such initial properties of the alloys as ultimate strength and thermal creep resistance, hardness, thermo cycling stability, phase and structural thermal stability can characterize and increased resistance of the alloys to gas swelling. At the same time increase in content of alloying additives optionally gives favorable results. As seen from Fig. 2, increase in $\mathrm{Zr}$ content, for example from 2 to $8 \mathrm{wt} \%$, can bring about a significant increase in $\mathrm{S}$ values instead of its decrease:

$$
\begin{aligned}
& \mathrm{B}=1.1 \ldots 3.9 \% \text { h.a } \\
& \mathrm{T}_{\text {irr }}=500 \ldots 630^{\circ} \mathrm{C} \\
& \omega=(3 \ldots 10) \cdot 10^{13} \text { fissions } /\left(\mathrm{cm}^{3} \cdot \mathrm{sec}\right)
\end{aligned}
$$

Stable favorable effect is achieved in case of higher $\mathrm{Zr}$ content $(\geq 10 \mathrm{wt} \%)$, which provides stabilization of isotropic gamma-phase in U-Zr alloy.

However, this effect is insufficient to prevent the swelling fuel column from contact and mechanical pressure on the cladding. 


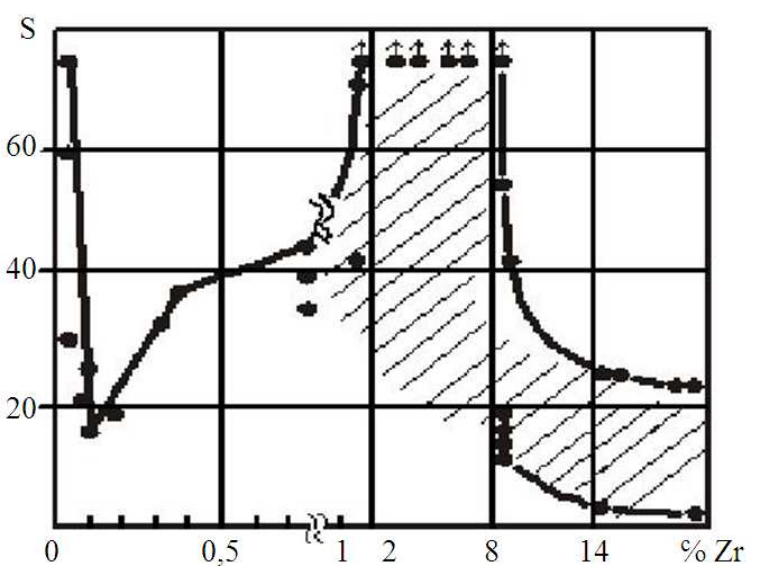

Fig. 2. Dependence of swelling of uranium and uranium with $0.1 \%$ al additives on zirconium content

In this connection, the investigations of mechanical pressure induced by fuels, which are the most resistant $\left(\mathrm{U}-0,5 \% \mathrm{BeO} ; \mathrm{S}^{600^{\circ} \mathrm{C}}=10\right)$ and the least resistant $(\mathrm{U}$; $\left.\mathrm{S}^{600^{\circ} \mathrm{C}}>60\right)$ to gas swelling were performed. Swelling stresses $\sigma_{\mathrm{S}}{ }^{600^{\circ} \mathrm{C}}$, calculated for these fuels differing in free swelling rate by factor of 6 , were also different but to a lesser degree and had insignificant absolute values $\left(\sigma_{\mathrm{S}}{ }^{600^{\circ} \mathrm{C}} \geq(5 \pm 1) \mathrm{MPa}\right)$.

The results of these experiments provide evidence for possibility of restraining macroeffects of radiation swelling of metal fuel column by constructive methods, which do not involve necessity of the swelling rate decrease as a result of fuel alloying and thermal treatment. These methods must provide sufficient mechanical strength of the cladding, in which metal fuel column can be considered thick liquid. In this case the initial shape of the fuel column can be varied.

\subsection{FCCI Effects (Metal Fuel-Steel Cladding)}

Risks of physical-chemical (metallurgical) interaction between metal Fuel Column and Steel Cladding (FCCI), being in intimate contact, can be lowered differently-by metallurgical, constructive or combined methods. It is important, that the selected method should be not only sufficiently reliable, but also simple enough, which is necessary for its applicability during fuel pin fabrication under hot cell conditions.

The metallurgical method developed and applied at ANL is the most famous. It is based on doping uranium and $\mathrm{U}-\mathrm{Pu}$ alloys with $\mathrm{Zr}$ additive (10\%wt) (Kittel et al., 1993).

It is obvious, that this method is not simple, as there is need for monitoring such initial parameters as content and distribution of alloying additives in fuel columns under hot cell conditions. Unfavorable radiation-thermal effects of radial $\mathrm{Zr}$ redistribution are also known (Steele et al., 1989).

As for reliability of the method, its high potentiality established during out-of-pile tests at temperatures as high as $800^{\circ} \mathrm{C}$, was not confirmed at much lower temperatures during irradiation. It is reported (Cohen et al., 1993), that in EBR-II fuel pins irradiated up to the burnup 5-10\%h.a., depth of corrosion damage for HT-9 claddings, being in close contact with the fuel column (U-19Pu-10 Zr wt.\%), was as high as 33$57 \mu \mathrm{m}$ at cladding temperatures about $550^{\circ} \mathrm{C}$.

During fabrication of high active fuel pins "constructive" approaches to FCCI reduction are considered simpler, as they do not imply quality control of fuel pin components in the hot cells. These methods comprise: application of bimetallic claddings of "steelvanadium" or "steel-zircaloy-2" types, filling of intermediate thin-wall $\mathrm{Zr}$ cladding with fuel alloy $\mathrm{U}-\mathrm{Zr}$ or U-Pu-Zr (Tokiwai et al., 1993; Crawford et al., 1993).

As for reliability of the simple methods under consideration, the following should be noted. In-pile tests of metal fuel pins having bimetallic claddings were not performed. No expected favorable results were obtained from in-pile tests of the fuel pins containing fuel in zirconium cladding (Crawford et al., 1993).

Developed at RIAR methods for FCCI reduction can be considered simple, as there is no need for quality control of fuel pin components under hot cell conditions.

The methods are based on applying of protective metal (W, Cr) layers on the inner surface of steel claddings and/or protective nonmetal (oxide, oxicarbide) layers on the outer surface of fuel columns.

FCCI between uranium or U-Pu alloy fuel columns and austenitic stainless claddings (EI-847), which were constructively separated by means of the protective layers mentioned above, were studied during out-of-pile, in-pile tests and postirradiation examinations. During preparatory work and tests the following was varied:

- Initial characteristics of fuel, claddings, fuel pins $(\mathrm{Pu}$ content in fuel, composition and thickness of protective layers)

- Irradiation parameters (temperatures of cladding and fuel, linear generations, fuel burnup)

- Parameters of emergency overheatings (temperatures and durations of overheatings, types and size of intentional defects)

Some results of the investigations are provided in Fig. 3 and 4. 


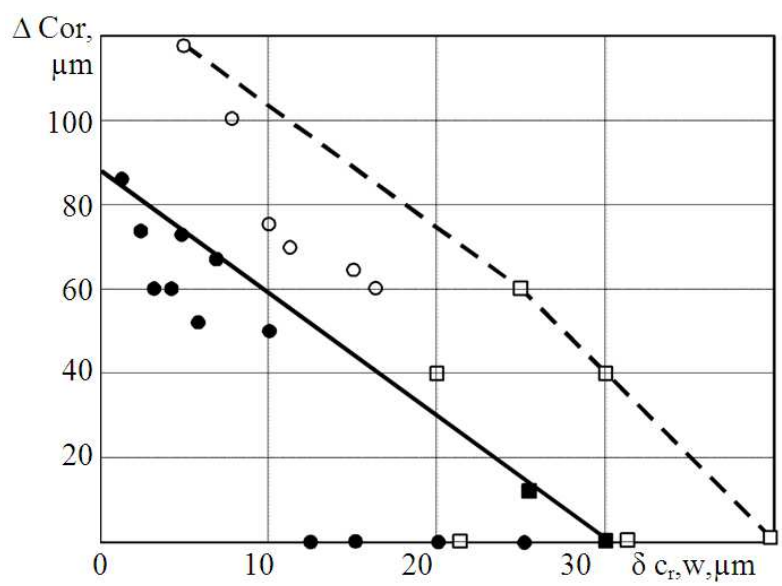

Fig. 3. Depth of corrosion damage of ei-847 claddings with protective layers $\mathrm{cr}(\mathbf{)})$ or $\mathrm{w}(\boldsymbol{\square})$ of different thickness

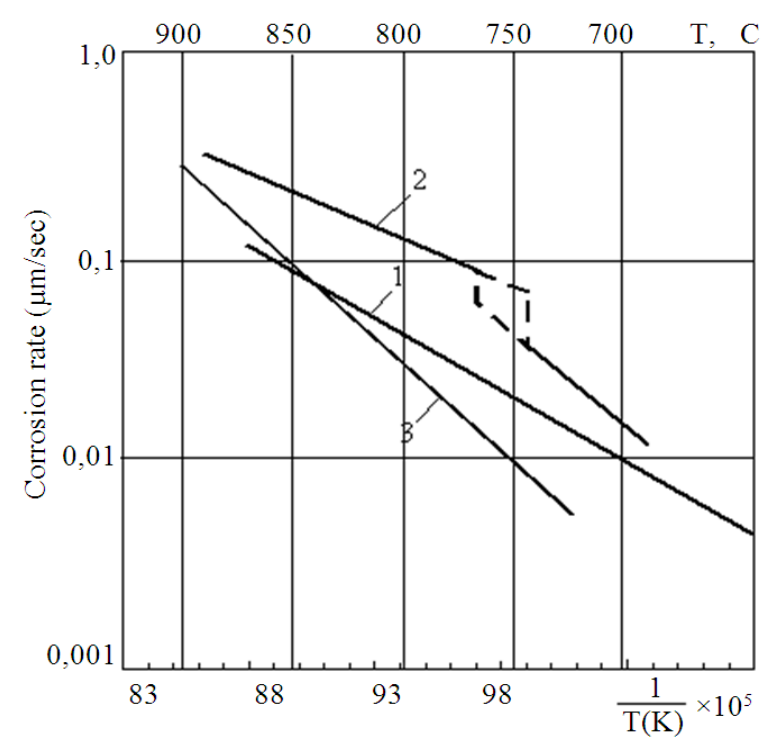

Fig. 4. Cladding corrosion rates as a function of postirradiation overheating temperature

Figure 3 (the upper dotted line) illustrates positive influence of such initial characteristics of fuel pins as thickness of metal protective layer on the inner surface of steel cladding upon FCCI decrease. The lower solid line illustrates effectiveness of application of auxiliary oxicarbide protective layer on the fuel column surface.

D, - the same, if fuel columns are protected with oxicarbide layer of $5 \div 10 \mu \mathrm{m}$ in thickness. Test parameters: Fuel column material: alloy U-(15 2 ) $\mathrm{Pu}$; $\mathrm{B}^{\max }=4,5 \div 6,8 \%$ h.a..; $\mathrm{T}_{\text {clad }}{ }^{\max } \leq 630 \pm 50^{\circ} \mathrm{C}$
Figure 4 presents comparison of corrosion damage rates for claddings of fuel pins of different types under emergency overheating.

1 -fragments of the fuel pins irradiated in EBR-II (U-19Pu-10Zr/HT-9), $\mathrm{B}^{\max }=5,6 \div 11 \%$ h.a.; 2-fullsize fuel pins, irradiated in BOR-60 (U-15Pu/EI-847), $\mathrm{B}^{\max }=6,8 \%$ h.a.; 3-the same, the cladding has the protective $\mathrm{W}$ layer.

Line 1 agrees with the developed and tested at ANL fuel pins with "metallurgical" method of FCCI decrease (fuel column-U-19\% Pu-10\% Zr, cladding-ferriticmartensitic steel HT-9, Na-filling) (Cohen et al., 1993).

Line 3 agrees with the developed and tested at RIAR fuel pins with "constructive" method of FCCI decrease (fuel column-U-15\% $\mathrm{Pu}$, cladding-austenitic steel EI-847 with $\mathrm{W}$ layer on the inner surface, He-filling).

Line 2 corresponds with the fuel pins, in which no methods of FCCI decrease were applied.

Pair comparison of these lines shows, firstly, high effectiveness of using both metallurgical (fuel alloying with $\mathrm{Zr10} \% \mathrm{wt}$ ) and "constructive" methods (application of W-layer on the inner surface of the cladding). Secondly, one can see, that the cladding protection with $\mathrm{W}$ layer is not less effective than alloying of fuel with zirconium within the whole range of practically important temperatures of the cladding $\mathrm{T}_{\text {clad. }} \leq 825^{\circ} \mathrm{C}$.

\subsection{Irradiation of Experimental Fuel Pins in the BOR-60 and Bn-350 Reactors}

The established peculiarities and laws of influence of initial uranium and uranium-alloy characteristics on effects of radiation growth, swelling and FCCI were used during development, fabrication and irradiation of elements of various types and purposes in the BOR60 and $\mathrm{BN}-350$ reactors.

By purposes the elements are subdivided into:

- Radial Blanket Elements (RB)

- Axial Blanket elements (AB)

- Absorber rods for Burnup Controller (BC)

- Geterogenizating elements for oxide-metal core under Intra-Fuel Pin, Intra-Assembly and Assemblyto-Assembly Heterogenization (IFPH, IAH, AAH)

- Fuel pins for the core

In all listed above types "constructive" approaches were used for neutralization of unfavorable initial characteristics of U-alloy fuels, namely:

- Mechanical restraints of radiation growth macroeffects by means of steel cladding in fuel 
columns having $\alpha$-phase $U$ structure, coarse grains or texture of directed radiation growth in the initial state

- Mechanical restraints of radiation swelling macroeffects by means of steel cladding in fuel columns having $\alpha$-phase $U$ structure, different $\mathrm{Pu}$ content and differing in geometry, structure and texture in the initial state

- Mechanical separation of fuel columns from claddings with the protective layers-metal $(\mathrm{Cr}, \mathrm{W})$ and/or nonmetal (oxide, oxicarbide), applied on the inner surface of claddings and outer surface of fuel columns, correspondingly

In-pile tests of the elements by purposes were subdivided into:

- Comparative-for comparing radiation-thermal effects at varying initial characteristics of fuel, fuel columns, elements

- Forced-for studying radiation-thermal effects in the elements with beyond design basis initial fuel characteristics and irradiation parameters of fuel pins

- Standard-for validation of experimental elements reliability under standard operating conditions of BOR-60 and BN-350

About 100 full-size FA incorporating more than 3000 experimental elements were tested on the whole. Most of the FA after comparative and forced tests and some FA after standard tests were subjected to postirradiation examinations.

In the course of in-pile tests and PIE certain laws and interdependencies were found between initial characteristics of high-dense metal fuels and radiation-thermal effects in the experimental elements containing such fuels.

It was established, that at temperatures below $600^{\circ} \mathrm{C}$ macroeffects of $U$ radiation growth, namely, steel claddings deformations (roughening of surface, ovalization) are pro rata initial values of fuel column strength and inversely proportional to characteristics of design strength of claddings.

It was found, that some "unfavorable" initial characteristics of high-dense metal fuels such as intense radiation growth, intense radiation swelling, low-temperature phase transformations (bringing about volume increase) can be useful for restraining such undesirable radiation-thermal effects as axial movement and elongation of fuel column inside the cladding, fuel column overheating, axial mass transfer of fuel inside the cladding.
It was found, that corrosion damage of steel claddings, caused by high-dense fuel columns (FCCI), obeyed the laws of volume diffusion, i.e., had a frontal nature. This FCCI type is unchangeable during irradiation, including under emergency overheating of fuel column up to melting.

It was established, that during emergency overheating a formation of liquid eutectics $(\mathrm{U}, \mathrm{Pu})(\mathrm{Fe} \mathrm{Ni})_{2}$ $(\mathrm{U}, \mathrm{Pu})_{6}(\mathrm{Fe}, \mathrm{Ni})$ in the zone of "fuel column-tungsten protective layer-cladding" was accompanied neither by dissolving protective tungsten layer nor changing FCCI type, but it is accompanied by foaming liquid eutectics.

Standard in-pile tests of the experimental FA were performed in the BOR- 60 and $\mathrm{BN}-350$ reactors by direct replacement of the standard $\mathrm{FA}$ by the $\mathrm{FA}$ of the corresponding purpose (RB, AB, BC, IFPH, IAH, AAH, Core) without changing the operating modes of the reactors. During in-pile tests, no untimely termination of the experimental elements was observed, neither failure nor loss of integrity were found.

Integrity and leak-tightness of the elements were confirmed during PIE. Simultaneously, influence of initial characteristic of fuel columns on radiation-thermal effects in the experimental elements were verified and improved in the course of comparative and forced tests.

Initial characteristics of intense radiation growth of quasiisotropic macrocrystalline fuel columns and finegrain fuel columns with initial texture showed up in surface roughening and ovalization of steel claddings of RB elements. These macroeffects, however, did not tell on integrity and leak-tightness of the elements.

Initial parameters of intense radiation growth, intense radiation swelling and low-temperature phase transformations in high-dense fuel columns showed up in macroeffects of mechanical "jamming" of fuel columns in claddings at initial irradiation stages. During the subsequent stages the initial macroporosity in cross section of the elements transformed into uniformly distributed microporosity. Fuel column "jamming" in the cladding provided absence of axial movement and retaining of initial fuel column height. Radially directed swelling of fuel columns ("anisotropic" swelling) had an insignificant influence on inelastic deformation of the claddings (Golovchenko, 2010).

FCCI layer thickness in the elements under study was within $90-120 \mu \mathrm{m}$, which is close to the admissible FCCI values for oxide fuel pins and alloyed metal fuel pins. As seen from Fig. 3, FCCI layer thickness is inversely 
proportional to that of the applied protective layers and can be brought down to preset values by this way.

\section{CONCLUSION}

As a result of carried out investigations it was established, that influence of some "unfavorable" initial characteristics of metal U-containing fuels on radiationthermal effects in the $\mathrm{BN}$-elements could be restrained by "constructive" methods. These approaches imply neither alloying of fuel nor thermal-mechanical treatment of fuel columns. That is why, these approaches can be considered simpler and more applicable in hot cells, which are unavoidable for organization of close fuel cycle during solving of INPRO tasks.

\section{REFERENCES}

Buckley, S.N., 1966. Irradiation growth in alpha uranium. Harwell.

Cohen, A.B., H. Tsai and L.A. Neimark, 1993. Fuel/cladding compatibility in U-19Pu-10Zr/HT9clad fuel at elevated temperatures. J. Nucl. Mater., 204: 244-251. DOI: 10.1016/0022-3115(93)90223-L

Crawford, D.C., C.E. Lahm, H. Tsai and R.G. Pahl, 1993. Performance of U-Pu-Zr fuel cast into zirconium molds. J. Nucl. Mater., 204: 157-164. DOI: $10.1016 / 0022-3115(93) 90212-\mathrm{H}$
Emelyanov, V.S. and A.I. Evstyukhin, 1969. The Metallurgy of Nuclear Fuel: Properties and Principles of the Technology of Uranium, Thorium and Plutonium. 1st Edn., Pergamon Press, Oxford, pp: 549.

Golovchenko, Y.M., 2010. Some results of developments and Investigations of fuel pins with metal fuel for heterogeneous core of fast reactors of the BN-type. Energy Proc., 7: 205-212. DOI: 10.1016/j.egypro.2011.06.027

Kittel, J.H., B.R.T. Frost, J.P. Mustelier, K.Q. Bagley and G.C. Crittenden et al., 1993. History of fast reactor fuel development. J. Nucl. Mater., 204: 1-13. DOI: 10.1016/0022-3115(93)90193-3

Lahm, C.E., J.F. Koening, R.G. Pahl, D.L. Porter and D.C. Crawford, 1993. Experience with advanced driver fuels in EBR-II. J. Nucl. Mater., 204: 119123.

Steele, W.G., A.R. Wazzan and D. Okrent, 1989. Steadystate fission gas behavior in uranium plutonium zirconium metal fuel elements. Nucl. Eng. Des., 113: 289-295. DOI: 10.1016/0029-5493(89)90023$\mathrm{X}$

Tokiwai, M., M. Horie, K. Kako and M. Fujiwara, 1993. Development of new ferritic steels as cladding material for metallic fuel fast breeder reactor. J. Nucl. Mater., 204: 56-64. DOI: 10.1016/00223115(93)90199-9 